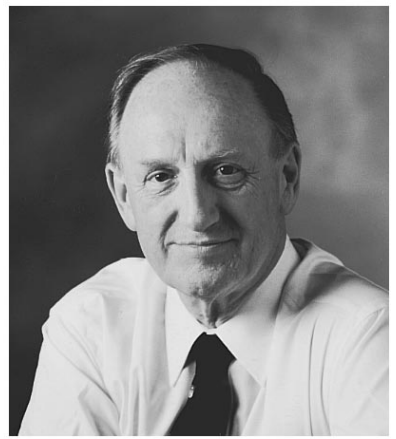

\section{Communication Channels: From Editor to Reviewer to Editor}

Many of the readers of this editorial will have interacted with me in my capacity as an editor, because they will have been reviewers for Optical Engineering. Selecting the appropriate reviewers is one of the major tasks of an editor, but that is only the start of the process.

The style for our journal is to send a paper to the potential reviewer with the following letter:

Re: OE

Dear

I sincerely hope you will be able to serve as a referee for the enclosed manuscript, which is being considered for publication in Optical Engineering. The review of manuscripts by impartial referees is an important step in the publication process, and your efforts will be a valuable contribution to the strength of the Journal. If you are able to accept the invitation, please return the white card to let me know when I can expect your review.

If you are unable to review the manuscript within the next three weeks or believe that you are not an appropriate referee for it, return the completed blue card with the manuscript so that I can locate an alternate reviewer. Your recommendation for an alternate reviewer will be appreciated. Please feel free to pass the manuscript to a colleague for review if that seems appropriate.

When you have completed your review, please send your report and the manuscript to me in the pre-stamped envelope. You may, of course, make annotations directly on the manuscript.

Thank you for your help.

Sincerely,

The letter mentions two cards. The "white card" is a stamped, addressed card shown in Fig. 1. The so-called "blue card"' is shown in Fig. 2. The other enclosure is a stamped envelope for the return of the manuscript with the blue card or return of the manuscript with the review. (Of course it is only possible for us to prepay the return postage within the United States.)

Recently I received a letter from a reviewer, who also happened to be a former editor. He said, "I do not envy you your job as editor, as I know well how difficult and time consuming it can be. By the way, how many other referees have sent back the white card you ask for? My experience was that most ignore the request, even if they do review the paper.'

This was a good question, so I decided to test the question against the facts and took a sample of 150 reviewers from the first quarter of 1995. Thirty-four percent of those reviewers returned the card; of these, $87 \%$ sent in their reviews on time without any further reminder from me. Another $17 \%$ of the original 150 did not return the card, but sent in their reviews in a timely manner, with the card often included with the review. My conclusion is that the "white card" is worthwhile and is a useful tool for this editor.

With $51 \%$ of the reviewers accounted for above, the editor has the task of following up with the remainder. Thirty-three percent of the 150 reviewers in this sample needed to be sent reminder cards. A few of these required a follow-up fax or letter saying "I urgently need your review please." There are, of course, a number of reviewers that I never hear from-in the sample it was $16 \%$. There are a number of reasons for that percentage. Sometimes the person has moved and I can't track them down, or they are on leave and the mail really does not catch up with them, etc. And finally, there are one or two who just never got around to it!

I must conclude this editorial by noting that I am very pleased with the response I get to my invitation to serve as a reviewer. Our colleagues are responsive and responsible-thank you.

\section{Editor's Anecdote}

I have mentioned previously in this column the various forms of address that I have been subjected to. None of them have been in any way mean-spirited; I like to put a positive interpretation on them and assume they are supportive and friendly (or is that my defense mechanism 


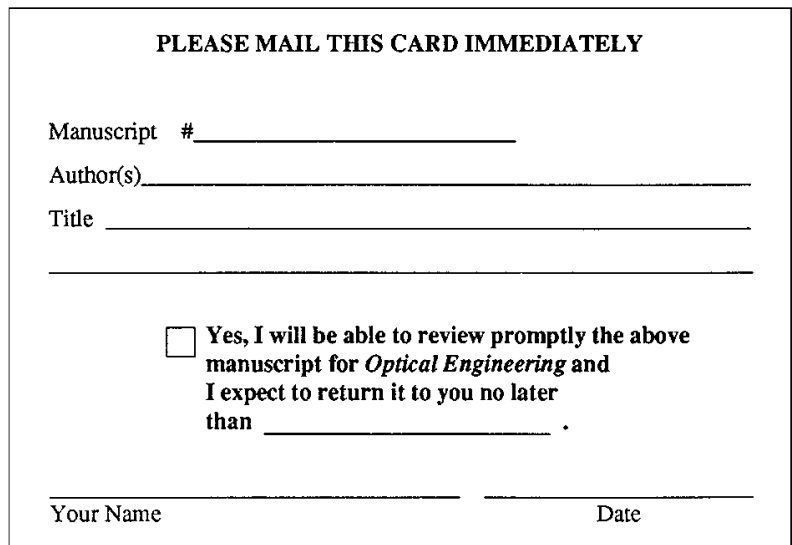

Fig. 1 The "white card."

working?). I added a new salutation to my list from a letter that merely started with "Dude." The only other time, to my knowledge, that this term has been used about me was when a former student told my assistant that I was "a mega-dude of optics." The term "dude" perhaps means something different than the dictionary definition when used in the vernacular. The dictionary definition of

\section{PLEASE RETURN THIS CARD WITH THE MANUSCRIPT}

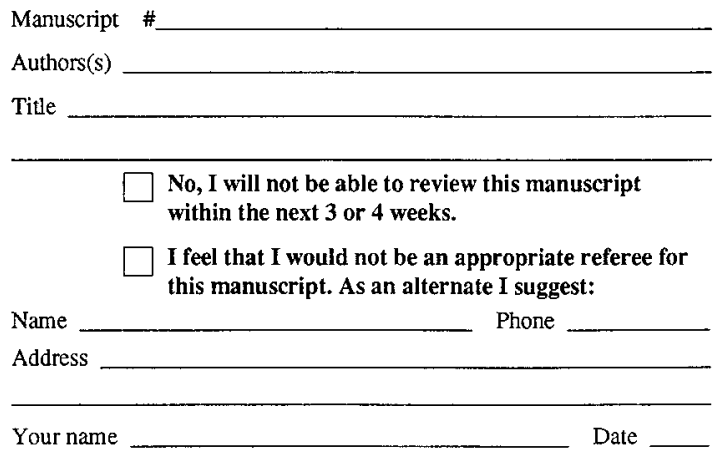

Fig. 2 The "blue card."

dude (whose origin is listed as unknown) is "a man extremely fastidious in dress and manner; a city man: an Easterner in the West" (from Webster's New Collegiate Dictionary).

Brian J. Thompson

Editor 